\title{
Los Adolescentes: sin respuestas simples
}

\author{
Notas de la conferencia \\ Dr. Alberto Morales Bejarano, médico pediatra \\ Presidente Asociación \\ Pro Desarrollo Saludable de la Adolescencia \\ Fundador y exjefe de la Clínica de Adolescentes \\ del Hospital Nacional de Niños
}

\begin{abstract}
El 17 de agosto, en el marco del III COLOQUIO: Re-conectándonos con la Adolescencia, realizado por la recién acreditada Maestría Profesional en Psicopedagogía de la Universidad Estatal a Distancia, el médico Alberto Morales realizó la apertura de la actividad con la Conferencia Los Adolescentes: sin respuestas simples.

Partiendo de preocupaciones y paradojas que se presentan a través del tiempo en relación con un futuro lleno de nuevos retos vinculados al desarrollo tecnológico, de la atención de salud integral de las personas adolescentes y de la nueva "morbilidad social", el doctor Morales hace un llamado a desarrollar planes y programas, dirigidos a este sector creciente de la población costarricense; y a recuperar y a fortalecer la oferta de consulta intersectorial diferenciada a cargo de equipos interdisciplinarios integrados y dedicados tiempo completo.
\end{abstract}

En 1986, la atención diferenciada en salud de la población adolescente costarricense (10 a 20 años) no se consideraba como una necesidad, e incluso las estadísticas vitales de nuestro país no tomaban este rango de edad como específico ni claramente definido.

En la época actual, a raíz de la mejora en la sobrevida de los pacientes con enfermedades crónicas y a la capacitación de profesionales en el campo de la adolescencia, en el Hospital Nacional de Niños, nace la primera clínica de adolescentes, conformada por un equipo interdisciplinario de profesionales, para brindar atención a este grupo etario, de manera diferenciada y ya no como parte indiscriminada de la población infantil.

Concomitante con la creación de la clínica, un grupo de profesionales de diversos sectores, que

\footnotetext{
${ }^{1}$ Educadora con énfasis en Informática Educativa, doctora en Educación con énfasis en Tecnología Instruccional y Educación a Distancia. Es catedrática de la Universidad Estatal a Distancia y coordina las maestrías en Educación a Distancia y en Tecnología Educativa. Es parte del Consejo Editorial de la Revista Posgrado y Sociedad.
} 
incluían salud, educación y social, conforman una primera comisión convocada por la presidencia ejecutiva de la CCSS de la época, y se elabora un primer diagnóstico de la situación de la adolescencia en Costa Rica.

Posteriormente y con el apoyo de la Organización Panamericana de la Salud, esa misma comisión plantea un proyecto que culmina con la creación, dentro de la CCSS, del Programa de Atención Integral de Adolescentes y la conformación de alrededor de 100 servicios diferenciados en salud para adolescentes, en varias provincias de nuestro país.

Dentro de ese proceso, surge una clara identificación de que las personas adolescentes reúnen características y tareas del desarrollo propias, las cuales, de forma clara, las diferencian de la población infantil y adulta; además, que sus necesidades habían sido desatendidas crónicamente. Los adolescentes no eran adultos pequeños ni niños grandes, tampoco eran solo el futuro, sino que eran actores sociales y sujetos de derechos en el presente.

De ahí, se plantea la importancia de generar estrategias, ya no solo del sector salud, sino intersectoriales e interdisciplinarias, que pudieran dar respuestas a las carencias existentes. Sin embargo y a pesar de este desarrollo conceptual y de servicios para adolescentes, coincidiendo con la reforma del sector salud en los años 1990 ocurre un progresivo desmantelamiento del Programa de Adolescentes de la CCSS.

El acontecimiento anterior hace que, en la actualidad, exista una consulta diferenciada para adolescentes, con equipos interdisciplinarios integrados y dedicados tiempo completo, es una excepción. Una de estas excepciones es la Clínica de Adolescentes del Hospital Nacional de Niños, más que un auténtico orgullo es un motivo de preocupación, ya que pone en evidencia la precaria situación de la atención en salud de adolescentes en nuestro país.

Esta situación de deterioro en los servicios de salud y de la necesaria coordinación intersectorial sucede en un marco de una mayor complejidad de la problemática que afecta a esta población y que se convierte en motivos de atención para el sector salud, pues la cobertura en salud no supera 33\% de esta población. Algunos ejemplos de estas problemáticas son los siguientes: enfermedades crónicas; drogadicción; violencia; embarazo y maternidad y paternidad adolescente; depresión y suicidio; anorexia y bulimia; enfermedades de transmisión sexual; bullying; fracaso escolar; disfuncionalidad familiar; entre muchos otros.

Sin un enfoque de atención integral brindada en equipo interdisciplinario y con la participación intersectorial, no se puede acometer los retos que representa la nueva "morbilidad", que algunos llamamos "morbilidad social", la cual impacta a las personas adolescentes. Esto implica que son necesarios profesionales de ciencias de la salud, ciencias sociales y educación, entre otros, para integrar verdaderos equipos interdisciplinarios, que permitan un acercamiento comprehensivo a estas situaciones complejas.

En nuestro país, nos enfrentamos a contradicciones importantes ante una mortalidad infantil de alrededor 7.55 por cada mil nacidos, una de las más bajas del continente americano, con un una atención prenatal y neonatal de primer mundo. Vemos como se empieza a dar un deterioro en la atención en salud a partir de la edad escolar y muestra su peor escenario en la etapa adolescente, donde incluso muchas de las personas que sobreviven por una excelente atención en la infancia, se enfrentan a un abandono de sus necesidades en la adolescencia, más si estas son necesidades especiales.

En la actualidad, Costa Rica tiene cara de persona joven, solo $10 \%$ de personas son adultas 
mayores; para el 2050, crecerá a 30\%. Como país, tenemos la gran oportunidad, pues en este momento, existe el mayor número de personas entre los 10 y 25 los años de toda nuestra historia. Esto que conocemos como el bono demográfico, se refleja en que, en 1960, por cada 100 personas económicamente activas (personas de 15 a 64 años), existían 105 dependientes; en 1990, era de 60 dependientes; y en la actualidad, de 43.

Si sabemos administrar esta única coyuntura histórica, garantizando salud, educación y protección para este segmento poblacional, las posibilidades de crecimiento económico, reducción de la pobreza, calidad de vida y enfrentamiento del envejecimiento pueden producir un cambio cualitativo social de gran envergadura. Pareciera que se olvida, además, que 38\% de las personas pobres son niños, niñas y adolescentes.

Haciendo este breve repaso, la pregunta que surge es por qué es tan difícil llevar a cabo planes y programas que beneficien a los adolescentes y jóvenes, si es más que evidente las necesidades crecientes de esta población y la desatención existente. Tiende a complejizar aún más este panorama el hecho de que, en desarrollo tecnológico, se habla ya de un IV Revolución industrial, con crecientes y exponenciales demandas en este campo, en donde $70 \%$ de los niños que están en primer grado de escuela tendrán trabajos que aún no se han inventado.
Signos de esperanza existen y un ejemplo de ello es el acuerdo de la Junta Directiva de la CCSS, del 23 de enero del 2017, de delegar, en el Programa de Adolescentes de la institución, la elaboración de una política y de un plan institucional para adolescentes en un plazo de 3 a 4 meses.

En ese trabajo, se ha avanzado y si se logra implementar, será un hecho histórico que puede revertir el abandono de dos décadas en salud de nuestros adolescentes. Sin embargo, persisten otras importantes debilidades para este sector poblacional, a saber: $50 \%$ de las personas de 18 a 24 años no han concluido su bachillerato; que solo $19 \%$ accede a educación superior; que, aproximadamente, $45 \%$ de los homicidios y muertes en carretera y $40 \%$ de los suicidios se dan en personas menores de 30 años, reflejo de lo que como sociedad hemos dejado de hacer.

Además, la magnitud de la desatención del grupo adolescente ha hecho que la problemática que debería haber sido resuelta en la adolescencia se traslape a edades posteriores; y esto se evidencia con las cifras de accidentes de tránsito, suicidios y homicidios, como víctima y victimarios, en personas de 20 a 25 años.

Trabajo estimulante por delante hay de sobra y esta importante actividad es un espacio de reflexión y de influencia, en beneficio de nuestros adolescentes y jóvenes. 
